\title{
Inquérito soroepidemiológico de dengue em dois municípios do Estado do Acre, fronteira Brasil - Bolívia
}

\author{
M aria $\mathrm{H}$ elena Guimarães ${ }^{1}$ \\ Pedro Fernando da Costa Vasconcelos ${ }^{2}$ \\ M árcio Roberto Teixeira N unes ${ }^{2}$ \\ Sueli Guerreiro Rodrigues ${ }^{2}$ \\ Davi Tanajura ${ }^{3}$ \\ JoséTavares-N eto ${ }^{3}$ \\ Edilândio D amasceno 4
}

\begin{abstract}
Resumo
Amostras séricas de 320 pessoas das cidades deB rasiléia eE pitaciolândia, fronteira Brasil (Acre)-Bolívia, foram testadas, pelos métodos de IgM -ELISA elgG-ELISA, em período posterior as epidemias de dengue ocorridas em 2000 pelos sorotiposD EN -1 eDEN -2. A prevalência deportadores deanticorposI gM foi de60,3\% e67,2\% del gG esomente 15,0\% foram co-soronegativos. A soropositividade foi maisfreqüente entreindivíduos do sexo masculino (70\% I gM ; $78,2 \%$ IgG ) enasfaixas etárias mais avançadas ( $p<0,0005$ ). Entre as pessoas sem história de dengue anterior, $62,2 \%$ e $66,7 \%$, respectivamente, foram I gM elgG positivos. A estimativa desubnotificação da infecção foi de $65 \%$ em Brasiléia, e69,9\% em E pitaciolândia. Em conclusão, a elevada prevalência deinfecção prévia eas características regionaisfacilitam a introdução denovos sorotipos do vírus da dengue, o que coloca a população daquelas cidades sob risco de ocorrência decasos de denguehemorrágico.
\end{abstract}

Palavras-chave: dengue; soroepidemiologia; estado do Acre; Brasil.

\section{INT RO DUÇÃO}

Após a epidemia de dengue na cidade de Boa Vista (Roraima) em 1981, pelos sorotipos 1 e $4^{1}$, o sorotipo 1 (DEN-1) do vírus da dengue voltou a circular no Brasil em 1986 pela cidade do Rio de Janeiro², bem como o sorotipo 2 (DEN-2) em $1990^{3}$ e o DEN -3 a partir de dezembro de $2000 .^{4}$
No Estado do Acre, os casos de dengue, anteriores a novembro de 2000, eram importados, inclusive da cidade boliviana de Cobija, onde ocorreu epidemia em dezembro de 1999 e que tem limites com as cidades acreanas de Brasiléia e Epitaciolândia. No Estado do Acre, o primeiro surto epidêmico de dengue foi iden-

\footnotetext{
${ }^{1}$ Secretaria de Estado de Saúde do Estado do Acre. Rio Branco - AC. Curso de M edicina. UFAC. Ro Branco - AC

${ }^{2}$ Instituto Evandro Chagas, Seção de Arbovírus. Belém - PA

${ }^{3}$ Faculdade de M edicida da Bahia. UFBA. Salvador - BA

${ }^{4}$ UFAC. Rio Branco - AC

Correspondência para / Correspondence to:

Prof. José Tavares-N eto

Faculdade de Medicina da Bahia - UFBA

Largo do Terreiro de Jesus

400026-010. Salvador - BA - Brasil

E-mail: tavaneto@ufba.br
} 
tificado na 51a semana epidemiológica de 2000, atingindo as populações dos municípios de Rio Branco, Senador Guiomard, Brasiléia e Epitaciolândia. Em Rio Branco, a epidemia re sultou em 1.030 casos confirmados de dengue pelos sorotipos DEN-1 e DEN-2, e um total de 2.878 diagnósticos confirmados até janeiro de $2001 .^{5}$

As cidades de Brasiléia e Epitaciolândia possuem extensa área de fronteira fluvial e terrestre com a cidade de Cobija (Estado de Pando, Bolívia), e têm ligação terrestre (rodovia AC317) com a cidade de Rio Branco e o restante do Brasil. Portanto, são consideradas áreas de risco de introdução e dispersão de agentes patogênicos à saúde humana. Tal fato motivou o estudo da prevalência de portadores de anticorpos contra 0 vírus da dengue nas populações dos dois municípios, associando-se os resultados sorológicos ao histórico clínico das pessoas, amostradas, após o período da epidemia de dengue.

\section{MATERIAL E MÉTODOS}

\section{Área de estudo}

Os municípios de Brasiléia e Epitaciolândia são separados geograficamente pelo Rio Acre e mantêm estreito vínculo cultural e socioeconômico. As sedes desses dois municípios acreanos distam em torno de $2 \mathrm{~km}$ da cidade de Cobija (capital do Estado de Pando, Bolívia), sendo ligada a essa cidade por uma fronteira "seca". N a época do estudo, de 5 a 18 de outubro de 2001, as cidades de Brasiléia e Epitaciolândia apresentavam população nas sedes urbanas de 8.047 e 6.623 habitantes, respectivamente. ${ }^{6}$

\section{C ritérios de seleção}

Para a realização do estudo transversal, as pessoas foram selecionadas aleatoriamente. Inicialmente, os quarteirões de todos os bairros de cada cidade (Brasiléia e Epitaciolândia) foram sorteados conforme os mapas fornecidos pela Coordenação Regional da Fundação $\mathrm{N}$ acional de Saúde (FUNASA) no Estado do Acre. Dos quarteirões sorteados, selecionou-se o primeiro domićlio de cada dezena, observando a nume- ração da FU N ASA. Posteriormente, de cada domicílio selecionado foram listados os moradores com mais de 8 anos de idade, presentes no domicílio no momento da visita da equipe de pesquisa e residentes na área urbana (em um daqueles municípios) no período de janeiro a dezembro de 2000.

0 tamanho amostral mínimo foi calculado pelo progrma EPI-INFO, estimando-se a soropositividade (IgG) nas populações das duas cidades como de $40 \%$ e o desvio esperado de $\pm 10 \%$, para o intervalo de confiança (IC) de $99 \%$. Em cada estimativa do tamanho amostral, foi incluído o número total de habitantes de Brasiléia ( $n=8.047)$ e Epitaciolândia ( $n=$ $6.623)^{6}$ e, em ambos os cálculos, a amostra mínima foi de 129 moradores.

Da lista de moradores, uma pessoa foi sorteada e incluída no estudo, caso a mesma (ou o responsável legal) concordasse em participar, após assinar o Termo de Consentimento Livre e Esclarecido, aprovado pelo Comitê de Ética em Pesquisa da Fundação Hospital do Estado do Acre (Rio Branco, Acre). I nformações pessoais de cada indivíduo sorteado foram levantadas, correspondendo a: sexo, grupo racial (branco, mulato, negro ou mestiço de índio), grau de escolaridade (ou se era analfabeto), renda familiar (em salários mínimos), condições do domićlio, residência ou viagem para outro Estado (ao longo do ano 2000), história anterior ou atual de dengue e queixas associadas à síndrome do dengue clássico (febre, cefaléia, dor retroorbitária, mialgias e prurido). A variável "condição do domicílio" foi composta somando-se os escores das seguintes variáveis ${ }^{7}$ : (i) material predominante de construção da moradia; (ii) luz elétrica; (iii) abastecimento de água; (iv) destino do lixo e (v) destino dos dejetos.

C aso a pessoa sorteada não concordasse em participar do estudo, outra do mesmo domicílio era sorteada e, se também não houvesse a concordância, o domicílio era excluído. N esse caso, o domicílio de numeração subseqüente era incluído no estudo e, em seguida, procedia-se com a mesma sistemática anterior.

Após o preenchimento do questionáriopadrão de cada pessoa, foram coletados $10 \mathrm{ml}$ de sangue venoso sem anticoagulante. No Laboratório da FU N ASA de Brasiléia, as amostras 
de sangue foram centrifugadas $(2.500 \mathrm{~g}$ durante 10 minutos), e o soro dividido em três alíquotas. As alíquotas séricas e o coágulo (a ser utilizado em outro estudo) foram acondicionadas a $4{ }^{\circ} \mathrm{C}$ e transportadas para a cidade de Rio Branco, onde foram conservadas no LACEN AC a $-20^{\circ} \mathrm{C}$, até 0 encaminhamento para o Instituto Evandro Chagas, IEC (Belém, Pará).

\section{Sorologia}

As amostras séricas foram submetidas aos testes de MAC-ELISA e ELISA para deteç̧ão de anticorpos IgM e IgG, respectivamente, conforme descrições de Kuno E colaboradores ${ }^{8,9}$. Para o M AC-ELISA, a interpretação dos resultados foi realizada mediante comparação dos valores em densidade óptica (D O ) obtidos para as amostras e controles (positivos DEN 1 eDEN 2; etrês controles negativos) com o valor de corte $(0,200)$, sendo as amostras com D $0=0,200$ e D $0<0,200$ consideradas positivas e negativas, respectivamente. Para o IgG-ELISA, as amostras positivas foram aquelas com $D 0=0,15$ e as negativas com $D O<0,15$. N esse teste imunoenzimático (IgG), foram também usados soros-controles (1 positivo-forte, 1 positivo-fraco e 1 soronegativo). Q uanto à determinação do padrão de resposta sorológica, os soros com títulos ${ }^{3} 1: 81.920$ foram considerados como resposta sorológica secundária, e os soros com títulos até 1:40.960 foram considerados como resposta primária. ${ }^{10}$

\section{Análise estatística}

Para análise estatística, os dados foram registrados na planilha eletrônica do programa SPSS (versão 9.0 "for windows"), e os testes estatísticos aplicados conforme o tipo da variável estudada. Valores de probabilidade ( $p$ ) iguais ou inferiores a $5 \%(p £ 0,05)$ foram considerados significantes.

\section{RESULTAD OS}

Somente 7 pessoas se negaram a participar do estudo. Foram selecionadas 320 pessoas, sendo 177 (55,3\%) de Brasiléia e 143 (44,7\%) de Epitaciolândia. No conjunto, as freqüências de portadores de anticorpos IgM e IgG para 0 vírus da dengue foram, respectivamente, de
$60,3 \%(193 / 320)$ e $67,2 \%$ (215/320). Todos os soropositivos apresentaram respostas sorológicas primárias $£ 1: 40.960$. Na Tabela 1 , os resultados sorológicos foram distribuídos segundo o bairro de cada cidade, e os da cidade de Brasiléia tiveram distribuição desigual, para IgM $(p<0,0000006)$ e IgG $(p<0,002)$. N ão obstante, as freqüências de portadores de IgM $(p>0,15)$ e IgG $(p>0,34)$ foram semelhantes nas duas cidades, como também é mostrado na Tabela 1 .

Somente 15\% (48/320) da população estudada apresentaram-se como co-soronegativos (IgM elgG ) e 42,5\% (136/320) e tinham ambas as imunoglobulinas. As demais pessoas ou eram somente soropositivas para a IgM $(17,8 \%$; $n=57)$ ou para a IgG $(24,7 \% ; n=79)$. N as cidades de Brasiléia e Epitaciolândia, as prevalências de co-soronegativos foram, respectivamente, de $16,4 \%(29 / 177)$ e $13,3 \%(19 / 143)$. Desse modo, pode-se estimar o número de pessoas soropositivas (IgG e/ou IgM ) naquelas cidades, respectivamente, de $6.727(83,6 \%)$ e 5.742 $(86,7 \%)$.

$D$ evido à semelhança das soroprevalências $\left(c^{2}=0,60 ; p>0,43\right)$ nas populações das duas cidades, a Tabela 2 apresenta a amostra estudada em conjunto. Tanto para a IgM $(p<0,01)$ como para a IgG $(p \varangle 0,002)$, os soropositivos foram

Tabela 1- Local (bairro) de residência na população estudada, nas cidades de Brasiléia e Epitaciolândia, segundo a sorologia (ELISA) para a dengue.

\begin{tabular}{cccc}
\hline BAIRRO, ONDE RESIDE & & \multicolumn{2}{c}{ DENGUE (ELISA), n(\%) } \\
\cline { 3 - 4 } NA CIDADE DE: & N total $(\%)$ & $\operatorname{IgM} \oplus$ & $\operatorname{IgG} \oplus$ \\
\hline BRASILÉIA & $177(55,3)$ & $113(63,8)^{\mathrm{b}}$ & $115(65,0)^{\mathrm{d}}$ \\
Centro & $77(43,5)$ & $59(76,6)$ & $59(76,6)$ \\
Samauma & $44(24,9)$ & $28(63,6)$ & $28(63,6)$ \\
Leonardo Barbosa & $21(11,9)$ & $5(23,8)$ & $6(28,6)$ \\
Botequis & $18(10,1)$ & $17(94,4)$ & $11(61,1)$ \\
Outros & $17(9,6)$ & $4(23,5)$ & $11(64,7)$ \\
(p) & & $<0,0000006$ & $<0,002$ \\
EPITACIOLÂNDIA & $143(44,7)$ & $80(55,9)^{\mathrm{c}}$ & $100(69,9)^{\mathrm{c}}$ \\
Centro & $28(19,6)$ & $11(39,3)$ & $18(64,3)$ \\
Liberdade & $40(28,0)$ & $20(50,0)$ & $29(72,5)$ \\
José Hassen & $36(25,2)$ & $26(72,2)$ & $29(80,6)$ \\
Beira Rio & $11(7,7)$ & $5(45,4)$ & $7(63,6)$ \\
Outros & $28(19,6)$ & $18(64,3)$ & $17(60,7)$ \\
(p) & & $>0,06$ & $>0,43$ \\
\hline
\end{tabular}

N ota: (a) qui-quadrado; (b vs. c): $p>0,15^{a ;}$ ( $d$ vs. e): $p>0,34^{a}$. 
mais freqüentes entre as pessoas do sexo masculino, com respectivamente $70,0 \%(77 / 110)$ e $78,2 \%(86 / 110)$, enquanto no feminino, foram de $55,2 \%(116 / 210)$ e $61,4 \%(129 / 210)$. Entre os portadores de IgG, as pessoas do grupo racial negro foram mais freqüentemente $(p<0,02)$ soropositivas $(86,5 \%)$, sendo menos freqüente entre os brancos $(61,7 \%)$ e os mulatos $(67,9 \%)$. Porém essa mesma diferença não foi observada com a IgM ( $p>0,50)$, como também mostra a Tabela 2.

Tanto para a IgM como para a IgG, os soropositivos tinham média de idade significativamente maior, respectivamente $41,2 \pm 18,7$ anos $(p<0,001)$ e $41,4 \pm 17,8$ anos $(p<0,0001)$, ao serem comparados aos soronegativos (34,9 \pm 14,7 e 33,1 $\pm 15,3$ anos, respectivamente). A análise da idade por classe intervalar (TABELA 2) evidenciou que só aqueles com 56 anos ou mais de idade eram mais freqüentemente $(p<0,0005)$ portadores de IgM, enquanto a positividade para a IgG aumentou proporcionalmente com a idade $(p<0,02)$.
Entre os portadores de IgM , não houve diferença $(p>0,37)$ nos três níveis de escolaridade. $M$ as, para a IgG, houve a tendência $(p>0,08)$ de as pessoas com nível maior de escolaridade serem menos soropositivos $(52,6 \%)$. Ainda na Tabela 3, não houve diferença entre os portadores de IgM $(p>0,10)$ e IgG $(p>0,37)$ quanto à renda familiar em salários-mínimos. No entanto, as pessoas residentes em domicílios com melhores condições foram mais freqüentemente soropositivas $(p \varangle 0,004)$ para a IgM , apesar de a mesma diferença não ser observada entre os portadores de IgG $(p>0,26)$.

Com referência ao ano de 2000 , foi semelhante $(p>0,35)$ o relato de viagem ou residência em outra U nidade da Federação $(66,0 \%$; $35 / 53)$ ou não $(59,2 \% ; 158 / 267)$ entre os soropositivos para IgM. A mesma semelhança $(p>0,27)$ das freqüências, foi observada entre aqueles soropositivos para a IgG com viagem ou residência em $2000(73,6 \% ; 39 / 53)$ ou sem os mesmos relatos $(65,9 \% ; 176 / 267)$.

Tabela 2 - D ados demográficos da população amostrada de Brasiléia e Epitaciolândia, distribuídos conforme o resultado do exame sorológico (ELISA) para a dengue.

\begin{tabular}{|c|c|c|c|c|}
\hline \multirow{2}{*}{\multicolumn{2}{|c|}{ VARIÁVEL DEMOGRÁFICA }} & \multirow[b]{2}{*}{$\mathrm{n}$ total $(\%)$} & \multicolumn{2}{|c|}{ DENGUE (ELISA) } \\
\hline & & & $\operatorname{Ig} M \oplus$ & $\operatorname{Ig} G \oplus$ \\
\hline \multirow[t]{3}{*}{ SEXO, n (\%): } & Feminino & $210(65,6)$ & $116(55,2)$ & $129(61,4)$ \\
\hline & Masculino & $110(34,4)$ & $77(70,0)$ & $86(78,2)$ \\
\hline & (p) & & $<0,01^{\mathrm{a}}$ & $<0,002^{\mathrm{a}}$ \\
\hline \multicolumn{2}{|c|}{ GRUPO RACIAL $^{\mathrm{b}}, \mathrm{n}(\%)$ : Branco } & $149(47,0)$ & $91(61,1)$ & $92(61,7)$ \\
\hline & Mulato & $131(41,3)$ & $75(57,2)$ & $89(67,9)$ \\
\hline & Negro & $37(11,7)$ & $25(67,6)$ & $32(86,5)$ \\
\hline & (p) & & $>0,50^{\mathrm{a}}$ & $<0,02^{\mathrm{a}}$ \\
\hline \multicolumn{2}{|c|}{ IDADE (anos), Média ( \pm DP) } & $38,7( \pm 17,5)$ & $41,2( \pm 18,7)$ & $41,4( \pm 17,8)$ \\
\hline & $(\mathrm{p})$ & & $<0,001^{c}$ & $<0,0001^{\mathrm{e}}$ \\
\hline \multirow[t]{8}{*}{ FAIXA ETÁRIA, n $(\%)^{d}$ : } & $11 \longmapsto 19$ & $39(12,2)$ & $21(53,8)$ & $20(51,3)^{1}$ \\
\hline & $20 \longmapsto-28^{2}$ & $80(50,0)$ & $40(50,0)$ & $46(57,5)^{2}$ \\
\hline & $29 \mid-137^{3}$ & $44(13,8)$ & $26(59,1)$ & $30(68,2)^{3}$ \\
\hline & $38-\mid 46^{4}$ & $61(19,1)$ & $38(62,3)$ & $44(72,1)^{4}$ \\
\hline & $47-155^{5}$ & $36(11,2)$ & $20(55,6)$ & $27(75,0)^{5}$ \\
\hline & $56 \mapsto 64^{6}$ & $27 \quad(8,4)$ & $21(77,8)$ & $20(74,1)^{6}$ \\
\hline & $\geq 65^{7}$ & $33(10,3)$ & $27(81,8)$ & $28(84,8)^{7}$ \\
\hline & $(\mathrm{p})$ & & $<0,02^{\mathrm{a}(\mathrm{d})}$ & $<0,02^{\mathrm{a}}$ \\
\hline
\end{tabular}

N ota: (a) qui-quadrado; (b) excluídos 3 mestiços de índio (2 IgM $\AA$ e 2 IgG $\AA$ ); (c) soronegativos: $34,9 \pm 14,7$ anos; teste $t$ de Student $(F=9,371 p<0,02 ; t=3,36$ g.l. $=307,59)$; (d) $p>0,69$ (1 vs. 2); $p>0,43$ (3 vs. 4 vs. 5$) ; p>0,69$ (6 vs.7); $p>0,18$ ([1 + 2] vs. $[3+4+5])$ e $p<0,0005$ ([1+ $2+3+4+5]$ vs. $[6+7]$ ); (e) soronegativos: $33,1 \pm 15,3$ anos; $F=2,774 p>0,09$. 
O s soropositivos para I gM predominaram significativamente $(p<0,001)$ entre as pessoas com história recente de dengue $(76,6 \% ; 59 /$ 77), do que naquelas pessoas sem a mesma história $(55,1 \% ; 134 / 243)$, sendo não-significante $(p>0,52)$ as freqüências quando foram analisados os I gG -positivos, respectivamente, de 70,1\% (54/77) e 66,2\% (161/243).

$\mathrm{Na}$ Tabela 4, os soropositivos e soronegativos, para a IgM e IgG, foram comparados segundo os grupos de queixas (sintomas) clínicas. Aproximadamente metade $(46,9 \%)$ da população estudada (150/320) não se referiu a nenhuma queixa associada à síndrome viral da dengue; mas, nessa população, $62,0 \% \quad(n=93)$

Tabela 3 - Indicadores socioeconômicos da população amostrada de Brasiléia e Epitaciolândia (Acre), de acordo com o resultado da sorologia para dengue (IgM e IgG).

\begin{tabular}{|c|c|c|c|}
\hline \multirow{2}{*}{$\begin{array}{l}\text { INDICADORES } \\
\text { SÓCIO- } \\
\text { ECONÔMICOS }\end{array}$} & \multirow[b]{2}{*}{$\mathrm{n}$ total $(\%)$} & \multicolumn{2}{|c|}{$\begin{array}{c}\text { DENGUE (ELISA), } \\
\mathrm{n}(\%)\end{array}$} \\
\hline & & $\operatorname{Ig} M \oplus$ & $\operatorname{Ig} G \oplus$ \\
\hline \multicolumn{4}{|l|}{ ESCOLARIDADE } \\
\hline $\begin{array}{l}\text { Analfabeto }+1^{\circ} \text { grau } \\
\text { incompleto }\end{array}$ & $228(71,2)$ & $132(57,9)$ & $155(68,0)$ \\
\hline $\begin{array}{l}1^{\circ} \text { grau c ompleto }+ \\
2^{\circ} \text { grau incompleto }\end{array}$ & $54(16,9)$ & $36(66,7)$ & $40(74,1)$ \\
\hline $\begin{array}{l}2^{\circ} \text { grau completo }+ \\
\text { superior }\end{array}$ & $38(11,9)$ & $25(65,8)$ & $20(52,6)$ \\
\hline (p) & & $>0,37^{a}$ & $>0,08^{a}$ \\
\hline \multicolumn{4}{|l|}{$\begin{array}{l}\text { RENDA FAMILIAR } \\
\text { (em salários-mínimos) }\end{array}$} \\
\hline$\leq 1$ & $137(42,8)$ & $74(54,0)$ & $85(62,0)$ \\
\hline $1,1 \longmapsto 2,0$ & $89(27,8)$ & $55(61,8)$ & $64(71,9)$ \\
\hline $2,1 \longmapsto 4,0$ & $57(17,8)$ & $36(63,2)$ & $39(68,4)$ \\
\hline$\geq 4,1$ & $37(11,6)$ & $28(75,7)$ & $27(73,0)$ \\
\hline (p) & & $>0,10^{\mathrm{a}}$ & $>0,37^{a}$ \\
\hline \multicolumn{4}{|l|}{$\begin{array}{l}\text { CONDIÇÓES DO } \\
\text { DOMICÍLIO (pontos) }\end{array}$} \\
\hline $2 \longmapsto-4$ & $25(7,8)$ & $12(48,0)$ & $17(68,0)$ \\
\hline 5 & $63(19,7)$ & $27(42,9)$ & $37(58,7)$ \\
\hline 6 & $102(31,9)$ & $68(66,7)$ & $75(73,5)$ \\
\hline $7|-| 8$ & $130(40,6)$ & $86(66,2)$ & $86(66,2)$ \\
\hline (p) & & $<0,004^{a}$ & $>0,26^{a}$ \\
\hline
\end{tabular}

N ota: (a) qui-quadrado; (b) teste de M ann-W hitney: I gM $(p<0,004$; "mean ranks": soropositivos de 172,11 e soronegativos de 142,86); IgG ( $>>0,69$; "mean ranks": soropositivos de 161,8 e soronegativos de 157,8 ). e $66,7 \%$ ( $n=100)$ apresentaram, respectivamente, IgM e IgG positivas. A soropositividade para a I gM não foi associada $(p>0,14)$ a nenhum dos seis grupos de sintomas estudados, como mostra a Tabela 4. Todavia aqueles com história de mial gias associadas à febre e à dor retro-orbitária foram mais freqüentemente $(p<0,05)$ soropositivos por IgG.

\section{DISC USSÃO}

0 s resultados do estudo evidenciaram freqüências elevadas (IgM : 60,3\%; IgG : 67,2\%) de portadores de anticorpos contra os vírus da dengue nos municípios de Brasiléia e Epitaciolândia. Prevalências el evadas foram também relatadas em inquéritos sorológicos, reali-

Tabela 4 - História clínica referida pela população estudada, por ocasião da epidemia de dengue em 2000, e a sorologia (ELISA) para a dengue de amostra coletada em 2001.

\begin{tabular}{|c|c|c|c|}
\hline \multirow{2}{*}{$\begin{array}{l}\text { HISTÓRIA CLÍNICA } \\
\text { RECENTE }\end{array}$} & \multirow[b]{2}{*}{$\mathrm{n}$ total $(\%)$} & \multicolumn{2}{|c|}{ DENGUE (ELISA), n(\%) } \\
\hline & & $\operatorname{IgM} \oplus$ & $\operatorname{Ig} G \oplus$ \\
\hline \multicolumn{4}{|l|}{ CEFALÉIA + FEBRE } \\
\hline Sim & $134(41,9)$ & $76(56,7)$ & $89(66,2)$ \\
\hline $\begin{array}{l}\text { Não } \\
(p)^{a}\end{array}$ & $186(58,1)$ & $\begin{array}{c}117(62,9) \\
>0,26\end{array}$ & $\begin{array}{c}126(67,7) \\
>0,80\end{array}$ \\
\hline \multicolumn{4}{|l|}{$\begin{array}{l}\text { DOR RETRO-ORBITÁRIA } \\
+ \text { FEBRE }\end{array}$} \\
\hline Sim & $89(27,8)$ & $53(59,6)$ & $61(68,5)$ \\
\hline Não & $231(72,2)$ & $140(60,6)$ & $154(66,7)$ \\
\hline$(\mathrm{p})^{\mathrm{a}}$ & & $>0,86$ & $>0,74$ \\
\hline \multicolumn{4}{|l|}{ MIALGIAS } \\
\hline Sim & $122(38,1)$ & $75(61,5)$ & $89(73,0)$ \\
\hline Não & $198(61,9)$ & $118(59,6)$ & $126(63,6)$ \\
\hline$(p)^{a}$ & & $>0,73$ & $>0,08$ \\
\hline \multicolumn{4}{|l|}{ MIALGIAS + FEBRE } \\
\hline Sim & $103(32,2)$ & $64(62,1)$ & $74(71,8)$ \\
\hline Não & $217(67,8)$ & $129(59,4)$ & $141(65,0)$ \\
\hline$(p)^{a}$ & & $>0,64$ & $>0,22$ \\
\hline \multicolumn{4}{|l|}{$\begin{array}{l}\text { MIALGIAS + FEBRE + } \\
\text { DOR RETRO-ORBITÁRIA }\end{array}$} \\
\hline Sim & $83(25,9)$ & $53(63,9)$ & $63(75,9)$ \\
\hline Não & $237(74,1)$ & $140(59,1)$ & $152(64,1)$ \\
\hline$(p)^{a}$ & & $>0,44$ & $<0,05$ \\
\hline \multicolumn{4}{|l|}{ PRURIDO + FEBRE } \\
\hline Sim & $38(11,9)$ & $27(71,0)$ & $30(79,0)$ \\
\hline Não & $282(88,1)$ & $166(58,9)$ & $185(65,6)$ \\
\hline$(p)^{a}$ & & $>0,14$ & $>0,10$ \\
\hline
\end{tabular}

N ota: (a) qui-quadrado. 
zados em grandes centros urbanos do Brasil, como no Rio de Janeiro, ${ }^{11}$ Fortaleza, ${ }^{12}$ Araguaina, ${ }^{13}$ Ribeirão Preto, ${ }^{14}$ São Luis $^{15}$ e Salvador ${ }^{16}$.

Em localidades de menor porte, como as cidades de Brasiléia e Epitaciolândia, foi realizado estudo semelhante nas cidades de I pupiara e Prado, no Estado da Bahia, ${ }^{17}$ onde as prevalências foram de $9,5 \%$ e $17,5 \%$, respectivamente. N aquele estudo, Vasconcelos e colaboradores atribuíram os resultados ao fato de os pequenos núcleos urbanos, ainda que deficientes em infra-estrutura de saneamento, propiciarem medidas mais eficazes de controle do vetor, por disporem também de menor proporção de utensílios potencialmente criadouros do Aedes aegypti. ${ }^{17}$

N ão obstante, não foi possível comparar as soroprevalências do presente estudo com as observados em outra população brasileira com características semelhantes, quais sejam, núcleo urbano de pequeno porte, mas incrustado em plena floresta tropical, de fácil acesso terrestre, e intercâmbio de atividades de trabalho, comerciais e de lazer com cidade de maior porte (Cobija, Bolívia), onde há aeroporto internacional, o que the confere características peculiares e comparáveis, em parte, àquelas pequenas cidades próximas aos grandes centros urbanos e que sofrem processo de metropolização.

A soroprevalência de $60,3 \%$ para IgM evidencia que tanto o DEN-1 como o DEN-2 permaneceram circulando intensamente nas duas cidades, contrariamente ao que se poderia esperar, desde que somente 52 e 57 casos de dengue foram notificados em Brasiléia e Epitaciolândia, respectivamente entre os períodos da 50a e 51a semanas epidemiológicas de $2000^{18}$ e a realização do presente inquérito, no período de 5 a 18 de outubro de 2001.

O s resultados de soroprevalência permitiram estimar que cerca de 6.727 pessoas em Brasiléia e 5.742 em Epitaciolândia, foram infectadas por um ou ambos os sorotipos do vírus dengue circulantes na região. As estimativas apresentadas evidenciam que a subnotificação dos casos de dengue em ambas as cidades foi muito elevada, ainda que considere a freqüência de $50 \%$ de infecções inaparentes ou assintomáticas. ${ }^{19}$ Sendo assim, o número esperado de casos notificados em 2000 e até outubro de 2001 seria de aproximadamente 3.312 [(6.727/2)-52] em Brasiléia e de 2.814 [(5.742/2)-57] pessoas em Epitaciolândia, considerando a população ${ }^{6}$ e 0 número de pessoas notificadas em cada cidade. ${ }^{18}$

A não especificidade do quadro clínico do dengue clássico, que freqüentemente é confundido com o de outras doenças febris ${ }^{20}$ e a baixa sensibilidade quanto à morbidade referida para a dengue, neste estudo, são fatores que podem estar também influenciando o sub-registro de casos.

As pessoas das faixas etárias mais elevadas apresentaram em Brasiléia e Epitaciolândia um risco maior de terem sido infectadas pelo vírus da dengue. 0 mesmo ocorreu em Salvador ${ }^{16} \mathrm{e}$ em São Luis do $\mathrm{M}$ aranhão, ${ }^{15}$ contrariamente aos achados de estudo em Fortaleza (C eárá). ${ }^{12}$

Os achados do presente estudo corroboram a hipótese de Teixeira ${ }^{16}$, que atribuiu a de sigualdade de padrões das epidemias ao tempo de circulação viral. Em Salvador ${ }^{16}$, tanto quanto em São Luis ${ }^{15}$, Brasiléia e Epitaciolândia, a introdução dos vírus circulantes era recente à época dos estudos, ao passo que em Fortaleza ${ }^{12}$ havia 10 anos do primeiro isolamento viral. Em conseqüência, a continuidade do processo de endemização do(s) sorotipo(s) sorotipo(s) circulantes reduz o contingente de pessoas susceptíveis, resultando em alteração do padrão inicial. ${ }^{16}$

Por sua vez, as pessoas com mel hores condições socioeconômicas e de domicílio foram mais positivas para IgM. Tal fato encontra semelhança com o estudo de Vasconcelos, Lima e Rosa ${ }^{12}$, que sugeriram ter a transmissão, nessas populações, características próprias, como maior uso de utensílios descartáveis e hábitos decorativos de plantas aquáticas, por exemplo. Por outro lado, a observação de mais soropositivos entre as pessoas do sexo masculino pode ser atribuído ao fato de que as atividades de trabalho, diferentemente dos grandes centros, é exercida no próprio domicílio ou nas proximidades, sujeitando-os, portanto, a maior exposição ao vetor. Não obstante, essa explicação não é satisfatória, porque dever-se-ia observar semelhante propor- 
ção de mulheres soropositivas. Portanto, não há explicação para a diferença na soropositividade entre as pessoas do sexo masculino e feminino dessas duas localidades do Estado do Acre.

Em conclusão, as soroprevalências observadas em Brasiléia e Epitaciolândia, bem como as séries históricas das epidemias de dengue no Brasi| ${ }^{21}$ e os índices de infestação predial do Ae. aegypti no Estado do Acre, em torno de 3,7\%,18 indicam a tendência de "endemização" do vírus da dengue nesse estado, à semelhança do que já ocorreu em grande parte do território nacional e em outras regiões do mundo. ${ }^{22} \mathrm{Em}$ conseqüência, como em outras regiões do Brasil, onde circulam dois ou mais sorotipos do vírus da dengue, também as populações remotas das regiões tropicais, a exemplo das de Brasiléia e Epitaciolândia, estão expostas ao risco de dengue hemorrágico, o que demonstra a necessidade de medidas de controle mais objetivas e conseqüentes.

\title{
Dengue seroepidemiology survey in two populations of Acre State, Brazil - Bolivia border
}

\begin{abstract}
Serum samples from 320 inhabitants from the cities of Brasileia and Epitaciolândia in Acre State (on the Brazil - Bolívia border) have been tested, using the ELISA method for IgM and IgG. These samples have been tested in the period after an epidemic of dengue in 2000 by serotypes DEN-1 and DEN-2. The prevalence of seropositivity for IgM was of $60.3 \%$ and $67.2 \%$ for IgG, and only $15 \%$ presented seronegativity. The positivity was most frequent among individuals of the male sex $(70 \% \mathrm{lgM}$; $78.2 \% \mathrm{lgG})$, and also in the older ages $(p<0.0005)$. Among the individuals with no history of dengue, $62.2 \%$ and $66.7 \%$ presented IgM and IgG antibodies, respectively. The estimative of subnotification of such infection is on the order of $65 \%$ in Brasileia and $69.9 \%$ in Epitaciolândia. In conclusion, the high prevalence of infection and the regional characteristics provide conditions for the introduction of new serotypes of dengue, which expose the population of such cities to the risk for the occurrence of dengue hemorrhagic fever.
\end{abstract}

Keywords. D engue. Seroepidemiology. State AcreBrazil.

\section{REFERÊNCIAS}

1 ROSA, A.P.A. Travassos da et al. Surto de dengue em Boa Vista, Território de Roraima, Brasil. Bol. Epidemiol. Ministério da Saúde, Brasília, DF, v.14, p.93-100, 1982.

2 SCHATZMAYR, H.G.; NOGUEIRA, R.M.; ROSA, A.P. Travassos da. An outbreak of dengue vírus at Rio de Janeiro, 1986. M em. Inst. O swaldo C ruz, Rio de Janeiro, v.81,p.245-246, 1986.

3 NOGUEIRA, R.M. et al. I solation of dengue virus type 2 in Rio de Janeiro. M em. Inst. O swaldo Cruz, Rio de Janeiro, v.85, p.253-254, 1990.

4 NOGUEIRA, R.M.R. et al. D engue virus type 3 in Rio de Janeiro, Brazil. M em. Inst.
O swaldo C ruz, Rio de Janeiro, v.96, p.925-926, 2002.

5 FUNDAÇÃO NACIONAL DE SAÚDE (Brasil). Sistema de Informação G erencial. Brasília, D F: M inistério da Saúde, [2001?] Disponível em:<www.funasa.gov.br $>$. Acesso em: 20 mar. 2002.

6 IBGE. Dados Populacionais: 2001. Rio de Janeiro, [2002?]. Disponível em: <www.ibge.gov.br>. Acesso em: 17 maio 2001.

7 GUIMARÃES, M.H. Inquérito soroepidemiológico de dengue em dois municípios do Estado do Acre, fronteira Brasil-Bolívia. 2002. D issertação (M estrado)- Universidade Federal da Bahia, Salvador, 2002. 
8 KUNO, G.; GÓMEZ, I. Factors influencing the transmission of dengue viruses. In: GUBLER, D.J.; KUN O, G. (Ed. Dengue and dengue hemorrhagic fever. $N$ ew York: $C A B$ International, 1997. p.61-88.

9 KUNO, G.; GÓMEZ; I.; GUBLER; D.J. Deteecting artificial anti-dengue IgM immune complexes using an enzyme-linked immunosorbent assay. Am. J. Trop. Med. H yg., McLean, v.36, p.153-159, 1987.

10 RO SA, A.P.A. Travassos da et al. Arboviroses. In: LEÃO, R.N.Q. (Ed.). D oenças infecciosas e parasitárias: enfoque amazônico. Belém: CEJUP, 1997. p.207-225.

11 FIGUEIRED 0, L.T.M.; CAVALCANTE, S.M .; SIM ÕES, M .C. D engue serologic survey of school children in Rio de Janeiro, Brazil in 1986 and 1987. Bull. Pan. Am. H ealth O rgan., Washington, D C, v.24, p.217-225, 1990.

12 VASCON CELOS, P.F.C.; LIMA, J.W.; ROSA, A.P.A. Travassos da. Epidemia de dengue em Fortaleza, C eará: inquérito soroepidemiológico aleatório. R. Saúde Pública, São Paulo, v.32, p.447-454, 1998.

13 VASCON CELOS, P.F.C. et al. Epidemia de febre clássica de dengue causada pelo sorotipo 2 em Araguaína, Tocantins, Brasil. R. Inst. Med. Trop. São Paulo, São Paulo, v.35, p.141-148, 1993.

14 FIGUEIRED 0, L.T.M. et al. Encuesta serológica sobre el dengue en Ribeirão Preto, São Paulo, Brasil. Bol. O ficina Sanit. Panam., Washington, DC, v.118, p.499-509, 1995.

15 VASCO N CELOS, P.F.C. et al. Inquérito soroepidemiológico na Il ha de São Luís durante epidemia de dengue no M aranhão. R. Soc. B ras. Med. Trop., Rio de Janeiro, v.32, p.171-179, 1999.
16 TEIXEIRA, M.G. D engue e espaços intraurbanos: dinâmica de circulação viral e efetividade de ações de combate vetorial. 2000. Tese (D outorado )- U niversidade Federal da Bahia, Salvador, 2000.

17 VASCON CELOS, P.F.C. et al. Epidemia de dengue em I pupiara e Prado, Bahia: inquérito soro-epidemiológico. R. Soc. Bras. M ed. Trop., Rio de Janeiro, v.33, p.61-67, 2000.

18 ACRE. Secretaria de Estado de Saúde e Saneamento. Coordenação de Vigilância Epidemiológica. Casos confirmados de dengue sorotipos DEN-1 e DEN-2. Bol. Epidemiol. Dengue, Rio Branco, ano 3, n.5, 2002.

19 CUNHA, R.V. et al. Secondary dengue infection in schoolchildren in a dengue endemic area in the state of Rio de Janeiro, Brazil. $\mathbf{R}$. Inst. Med. Trop. São Paulo, São Paulo, v.37, p.517-521, 1995.

20 GUBLER, D.J.; SATHER, G. Laboratory diagnosis of dengue and dengue hemorragic fever. In: IN TERN ATIO N AL SIM PO SIU M IN YELLOW FEVER AND DEN GUE, 1988, Rio de Janeiro. Proceedings.[ S.I.: s.n., 1988]. p.122-133.

21 FUNDAÇÃO NACIONAL DE SAÚDE (Brasil). Casos de dengue: Brasil por ano: série histórica. Brasília, DF: M inistério da Saúde, [200-?]. Disponível em: «www.funasa.gov.br>. Acesso em: 18 jun. 2002.

22 ORGANIZAÇÃO MUNDIAL DA SAÚ$D E .128$ a Sessão do Comitê Executivo Prevenção e C ontrole da D engue: CE 128/15. 2001. Disponível em: বhttp/:www.paho.org/spanish/ sha perfiles.htm>. Acesso em: 6 jun. 2002.

\section{Agradecimentos}

Às equipes da FUN ASA e das Secretarias M unicipais de Saúde de Brasiléia e Epitaciolândia, à Coordenação de Grandes Endemias e à coordenação de Vigilância Epidemiológica da Secretaria de Estado de Saúde do Estado do Acre.

\section{Apoio financeiro}

PET-M edicina (SESu/U FBA), CN Pq, IEC, FU N ASA-AC, FAPESB e Governo do Acre. 